\title{
Lenti-D/ABCD1-transduced Autologous Hematopoietic Stem Cells
}

National Cancer Institute

\section{Source}

National Cancer Institute. Lenti-D/ABCD1-transduced Autologous Hematopoietic Stem

Cells. NCI Thesaurus. Code C111902.

Autologous CD34+ hematopoietic stem cells transduced with Lenti-D lentiviral vector encoding the human ATP-binding cassette, sub-family $D$, member 1 (ABCD1) CDNA, for the potential treatment of childhood cerebral adrenoleukodystrophy (CCALD). Upon administration of the lenti-D/ABCD1-transduced autologous hematopoietic stem cells, the cells proliferate, and some travel to the brain and differentiate into microg lial cells. The expressed ABCD1 restores the function of ALD protein (ALDP) and aids in the treatment of CCALD. In CCALD, the ABCD1 gene is mutated, leading to the inability of patients to metabolize very long chain fatty acids in cells of the brain. 